\title{
La importancia de adaptar las traducciones y comentarios de los Lieder al lector meta como propuesta didáctica para mejorar la formación de los alumnos de canto
}

\section{The importance of adapting the translations and commentaries of lieder to the target reader, as a didactic proposal to improve the training of students of singing}

\author{
Ana Cristina de Castro Goñi \\ Universidad de Córdoba \\ z82csgoa@uco.es \\ https://orcid.org/0000-0001-8371-9464
}

Recibido: $14 / 09 / 2021$

Aceptado: 23/12/2021

DOl: https://dx.doi.org/10.12795/mAGAzin.2021.i29.02

\section{Resumen:}

La traducción del Lied es una tarea que entraña muchas dificultades y en numerosas ocasiones se olvida la importancia del texto cuando se interpreta vocalmente. Es primordial para una correcta interpretación vocal de una obra musical que el intérprete conozca en profundidad lo que está cantando, ya que el compositor ha elegido este texto porque ha influido en su vida y ha decidido musicalizarlo. Por esta razón, es tan significativo traducir, comprender y analizar desde diferentes puntos la intencionalidad tanto del autor de la obra literaria como del compositor. La música puede transmitir, transportar palabras y convertirlas en melodía sirviéndose del texto, pero si no se comprende el texto ni se adapta al lector meta (alumnos de conservatorios o escuelas de música) al que va dirigido, no servirá para entender la intencionalidad final de los creadores, lo que ayuda a los alumnos de canto a mejorar su interpretación.

Palabras clave: alemán, música, canción, literatura, traducción, interpretación.

\begin{abstract}
:
The translation of Lied is a very difficult task, and the importance of the text is often forgotten when it is interpreted vocally. It is essential for a correct vocal interpretation of a musical work that the interpreter knows in depth what he or she is singing, since the composer has chosen this text because it has influenced his or her life and has decided to set it to music. Therefore, it is so important to translate, understand and analyse the intentionality of both the author of the literary work and the composer from different points of view. Music can transmit, transport words and turn them into melody by using the text, but if the text is not understood and adapted to the target reader (students of conservatories or music schools) to whom it is addressed, it will not help to understand the final intentionality of the creators, which helps singing students to improve their interpretation.
\end{abstract}

Keywords: German, music, song, literature, translation, interpretation. 
a forma en la que un cantante interpreta una pieza musical puede convertir esa obra en una pieza exitosa o en un fracaso total sin que podamos explicar con conceptos estadísticos por qué se produce. Tampoco somos capaces de explicar el motivo por el cual una canción, cuya calidad puede considerarse mediocre, es capaz de emocionar a millones de almas, dependiendo de la persona que la interprete y otras, cuya calidad musical es muy superior, apenas tienen repercusión. Para lograr la integración de esas ideas dentro la interpretación es fundamental que el intérprete, no solamente sepa cuál es la temática de la canción, sino también otros aspectos sobre el compositor y letrista, sus influencias, inspiraciones, sus experiencias personales o el marco socioeconómico en el que ha vivido para que pueda entender la finalidad de la obra musical. Los traductores de Lieder tienen que dominar la lengua alemana, tener grandes conocimientos literarios (conocimientos técnicos a nivel morfológico y sintáctico), de la historia de la lengua alemana y saber plasmarlos en la lengua meta adaptándolos al alumno.

En el terreno de la música hay muchas obras que han sido compuestas basándose en un texto poético, como los impresionantes ciclos de Lieder compuestos por Schubert de autores como Goethe, Schiller o Heine entre otros muchos. Es un reto intentar contagiar a los alumnos en el aprendizaje de la lengua y cultura alemana a través de la traducción y comentario de los Lieder y no solo en aprendizaje de los componentes musicales. Esta fusión músico-literaria que está presente en los Lieder puede generar un nuevo enfoque educativo dentro de la enseñanza de la asignatura como «alemán aplicado al canto». Como define Carreras (2004: 30)

El trabajo del traductor ha sido ciertamente difícil. Como se ha repetido tantas veces, el traductor es prisionero del lenguaje que maneja y nuestra lengua, por desgracia lleva demasiado tiempo de vacaciones por lo que respecta a la música (Carreras 1998: 64).

Por este motivo, hace falta desarrollar estrategias significativas que impulsen la importancia de la enseñanza de la lengua alemana y estimulen la motivación de los alumnos en el aprendizaje de otras áreas relacionadas en este caso con la música; dando paso a la educación cultural y literaria (principalmente en los en los conservatorios y escuelas de música) a través de nuevos enfoques didácticos que impulsen la importancia de adecuar nuevas didácticas al lector meta.

\section{La fusión entre el texto y la música}

De aquí nace la necesidad de traducir y comprender los textos de los Lieder desde el punto de vista literario, ya que no sólo hay que tener en cuenta las diferencias en cuanto a contenido musical, sino también la necesidad que tienen los cantantes de conocer y entender la intencionalidad del autor del poema que dio lugar al Lied. La contextualización histórica, conceptos lingüísticos, gramaticales, literarios y experiencias personales de los autores de las obras enriquecen los conceptos estrictamente musicales a la hora de interpretar estas obras.

La música de forma independiente no es capaz de mostrar aspectos que evidencien la intencionalidad del letrista, el cual alcanza su máxima notoriedad en la descripción de los sentimientos más íntimos sobre temas como la noche, el amor, la expresión de los sentimientos frente a la razón o la sensibilidad del individuo como temas principales de los poemas románticos. Es primordial para la inspiración del compositor entender y comprender al autor del poema, y poder reflejar los sentimientos, pensamientos o influencias que quedan plasmados dentro del carácter de un poema. La perfecta empatía que se produce en una canción cuando el texto y la música se dejan seducir mutuamente para producir el Stimmung. El término Stimmung (traducido como afinación, química, conexión...) tiene un significado especial, se trata de un vocablo difícil de traducir al español, ya que describe la emoción que se siente una persona cuando una obra de arte ya sea un cuadro, una obra musical o literaria entra en contacto con la persona. 
La Stimmung es un conjunto de grafías fonéticas que describe progresivamente el armónico predominante en la pronunciación de cada vocal, ordenando las vocales según estos de más a menos armónicos y de menos a más. El hecho de que el material de base de Stimmung sea el círculo de las vocales -material fonético al fin y al cabo- da pie a que la significación musical de la obra se extienda hacia lo semántico. De las secuencias vocálicas surgen a menudo palabras con un significado concreto, casi siempre referidas a la mitología, a la naturaleza o a la sexualidad (Gomar 2005: 7-8).

Describe precisamente, esa unión donde la sensibilidad e intuición de un compositor para elegir un texto, musicalizarlo y producir otra creación artística. Por esta razón, es tan importante para los compositores elegir a sus "compañeros literarios" dentro de la creación de un nuevo trabajo poético-musical y donde la palabra Stimmung encuentra su máximo exponente. Convertir en poetas a los músicos, músicos en poetas al mismo tiempo para lograr un significado, intencionalidad, aspiración o finalidad de la obra deseada es un gran reto que muchas ocasiones no se llega a conseguir. Aunque quizás la definición que más encaje a estas afirmaciones la hace Charles du Bos cuando nos indica:

Presagio de condiciones psíquicas de naturaleza musical. La palabra designa al mismo tiempo la acústica del espíritu, dominio oscuro pero de gran importancia; la afinación de un instrumento y la disponibilidad del alma; y es en este punto de reunión de los dos sentidos, en su interpretación, donde tiene lugar el fenómeno; un espíritu en estado de Stimmung es espíritu afinado (Cardó 2017: 27).

\section{La concepción del Lied}

La palabra alemana Lied en singular, Lieder en plural, no es fácilmente traducible ya que puede significar en sentido general una canción original breve escrita para ser cantada. Definir el Lied es una tarea un poco más complicada que la definición o traducción de la palabra sacada del diccionario, ya que se trata de un término típicamente germánico. El Lied creado a partir del siglo XVIII es el tipo de canción en el que la fusión de la música con la poesía alcanzó su unión más íntima, basándose en los parámetros de la música francesa e italiana, donde se producen claras conexiones entre la canción popular Volkslied.

Los románticos alemanes llegaron a la conclusión de que añadiendo música a los poemas al estilo de las romanzas creaban una nueva concepción artística. Esta trilogía de los elementos (música instrumental, música cantada y letra que se canta) consigo en manos de genios como Schubert las cuotas más altas del arte moderno y contemporáneo (Reverte et al. 2008: 9).

Desde el punto de vista del texto, podría denominarse poesía musicalizada compuesta por un número equitativo de versos y estrofas, en el que el juego de las rimas y la regularidad de los acentos unido al carácter de sus significados poéticos predisponen a musicalizarse.

Si buscamos la relación entre el lenguaje y la música en la canción occidental nos sentiremos irritados al encontrar facetas tan diferentes y tropezamos en todas partes con contradicciones. Si bien constituye el lenguaje, como sucesión de sonidos dentro de la música, sin embargo, no tienen que constituir necesariamente una sucesión lógica del lenguaje. Lo que en el lenguaje ha de entenderse como una unidad indivisible necesita ser adapta de musicalmente primero. En esta contracción queda reflejado lo que nos obliga a reflexionar en la actuación conjunta del canto y el lenguaje (Fischer-Dieskau 1985: 12).

La profunda originalidad del Lied reside en transformar una obra literaria escrita, en una melodía acompañada de un piano dándole una esencia sublime. La intensidad que exige la poesía unida a la carga expresiva de la música produce una estructura formal que servía de placer estético para cantarse en los salones y reuniones de la sociedad de la época. Como ocurre con la literatura, la obra musical es una obra de arte que supone una íntima relación del texto musical con su autor, el cual crea una pieza musical junto a las estructuras establecidas y en torno a gustos estéticos, haciendo referencia a temáticas más humanas como pueden ser el amor, la angustia o el 
miedo o de la época que está viviendo.

Goethe lo describe en una hoja de su diario a Charlotte von Stein, el 7 de octubre de 1789: «No quiero investigar cómo ha surgido la melodía, me basta con que sirva admirablemente a un artista inspirado que tararee una canción y adapte a este canto los poemas que sabe de memoria» (Fischer-Dieskau 1985: 11). La concepción romántica de la música es un verdadero arte porque es el infinito en su esencia, ya que representa los sentimientos más íntimos del ser humano, la poesía se convierte en su fiel aliado y unidos forman el Lied, la nueva obra de arte que conmueve miles de almas.

El Lied plantea de la manera más aguda el problema clave de la relación entre la poesía y la música; tal como se plantea en el romanticismo alemán es un hecho cultural de extraordinaria importancia. La manera de entender lo más perdurable del romanticismo debe partir del Lied con su maravillosa alianza de libertad y precisión formal (Sopeña 1973: 14).

La época romántica en Alemania nace como rechazo a la razón ilustrada, donde el sentimiento, la reivindicación del talento y la creatividad condicionan la vida social del individuo, el cual se convierte en el verdadero centro de atención.

El romanticismo surge como reacción a los acontecimientos producidos en Europa por la Revolución Francesa, pero a diferencia de lo que pretendían otros estudiosos a los que Lukács dirige su crítica, afirma que no era un movimiento feudal, sino eminentemente burgués, que pretendía la transformación de Alemania hacia el régimen sin renunciar a los privilegios feudales (Pacheco y Vera 1998: 110).

Para Lukács, el Romanticismo es un movimiento completamente opuesto al Clasicismo de Goethe y Schiller, pues considera que uno y otro encarnan las dos posturas fundamentales y enfrentadas y que produce una profunda transformación de estructuras como consecuencia de los acontecimientos históricos que se estaban produciendo en Europa a raíz de la Revolución francesa.

Afirmar que el Lied es romántico y alemán es una tautología, y además es verdad. A partir de la primera década del siglo XIX y con Schubert es cuando el Lied -ese poema musical, esa canción original para ser cantada por una sola persona, esa manifestación artística en la que se funden música y poesía; son muchas las definiciones- adquiere plena identidad, y los grandes músicos buscan en textos de poetas contemporáneos esa fusión (Reverter et al. 2008: 110).

\section{Los autores de la canción}

En medio de una gran batalla en el siglo XIX por desarrollar el movimiento romántico, el Lied se expande a los salones privados para crear conciertos minoritarios, que no llega a las grandes multitudes como la ópera, pero a su vez creaba un clima de intimidad perfecto para esa unión entre el texto y la música dando lugar al florecimiento del Lied.

El origen del salón como foro cultural coincide con el ascenso de la burguesía como clase social. Ciudades tan importantes como Berlín no disponían lugares para el ejercicio de la cultura, a excepción de algunas asociaciones cerradas, de ahí que solamente pueda desarrollarse en el ámbito privado. El salón fue una de las formas preferidas para la relación social y la vida cultura, y en su centro siempre hubo una mujer. Los asiduos al salón pertenecían a diferentes clases sociales y les unían el gusto por conversas acerca de temas relacionados con la literatura, filosofía, política y muchas veces amenizados con música (Maldonado y Hernández 2003: 122).

El Lied se va adaptando a lo que el texto quiere expresar, de modo que suele resultar bastante cambiante dando lugar a la más alta expresión del arte vocal alcanzando el máximo refinamiento de la lírica. La utilización de estructuras más refinadas contribuyó a la expansión de este género dando paso a la profesionalización. Haydn, Mozart y Beethoven no serán recordados por sus Lieder (al contrario de Schubert o Schumann) aunque sí que escribieron algunos como Die Jahreszeiten (Las estaciones) de Haydn; Das Veilchen (La violeta) de Mozart o Ode 
an die Freude de Beethoven, el cual adopta esta idea con el espíritu de los jacobinos y simpatizantes cantaban la marsellesa junto con a la estrofa de An die Freude de Schiller. «La libertad y el amor lo conquistan todo» (Massin 1997: 199). Y como se define:

Este sentimiento de liberación proveniente del absolutismo francés que se sentia en los territorios germánicos había nacido al hilo de la Revolución francesa y los habitantes veían con esperanza la posibilidad de construir un nuevo Estado (Maldonado y Hernandez 2003: 118).

Aunque Zelter fue el compositor favorito de Goethe, este nunca fue capaz de comprender como lo hicieron Mozart, Beethoven o Schubert la riqueza del lirismo de su poesía. «Schubert no tenía ninguna necesidad de lo folclórico; se preocupó constantemente por hallar algo simple y profundamente sentido pero que a su vez llevará la marca de individualidad artística. Y esto es precisamente lo que encontró en Goethe» (Einstein 1986: 31). Schubert va a brillar de tal manera en la producción de Lieder que solamente podemos decir que poseía un talento innato para producir grandes obras maestras fusionando texto, música y canto. El poema pretendía significar mucho más, convirtiendo al texto en la parte principal del Lied. «La inspiración como misterio extendiéndose a la misma lectura de los poemas, el pasar con tal seguridad, con tal fuerza instintiva de Goethe a Heine, todo eso está patente en la sencillez de sus palabras» (Sopeña 1973: 37). El compositor estaba dotado de una increíble competencia armónica para modificar la esencia del poema, ya se tratase de un sencillo relato o poema, de solidos acentos poéticos o dotandolo de una sensacion o impacto fuera de las directrices del clasicismo. Pero si él sentia que el poema lo exigía, Schubert estaba dispuesto a sacrificar la métrica, rima para responder a los cambios de afecto, atmósfera o carácter del poema que él mismo había sentido cuando lo leyó, y que de alguna forma personalizaba los poemas de otros autores dándoles su propia personalidad basándose en sus propias viviencias o simplemente dejando libre a su creatividad a través de su impresionante talento musical.

Se ha afirmado que la canción artística o Lied constituye, a partir de Schubert, el primer género romántico completamente desarrollado. En efecto, en el clasicismo encontramos oposición dramática y resolución, desarrollada por una estructura musical basada en la tensión entre tónica y dominante. Ante la necesidad de musicalizar un texto de gran contenido lírico o dramático, Schubert introduce irregularidades armónicas y unas estructuras laxas que en algún grado rompen con los esquemas clásicos. Para producir un efecto, la canción puede no terminar en la tónica y una disonancia puede no resolverse. En cierto sentido es una reivindicación de la libertad del sujeto y expresa en la música un principio fundamental del romanticismo ya presente en la literatura y la filosofía: la subjetividad en acción (Valencia 2021: 9).

La personalidad de Schubert puede resultar fascinante y no se pueden obviar características atribuidas a este autor como la calidad vienesa de su música, la exuberante vena creadora, la fascinación de una invención melódica inconfundible o la práctica compositiva que era capaz de caracterizar a través de reiteraciones, asociaciones, transformaciones y sustituciones, que nunca se había oído. El músico, tomando consciencia de la actual diversidad frente al pasado, se siente incitado a una confrontación dialéctica; cada detalle adquiere su sentido en el desarrollo del Lied, aunque el sonido y la palabra no coincidiesen exactamente en cuanto a las estrofas, estas se mezclaban y complementaban componiendo bellísimas melodías perfectamente completadas sin grandes desarrollos ni elaboraciones.

\section{Propuesta metodológica}

\subsection{Búsqueda de información, lectura y comprensión de la obra}

La llegada de internet ha transformado la didáctica del aprendizaje, gracias al acceso inmediato a contenidos a través de los cuales obtenemos información para presentarnos nuevos conocimientos. Estas nuevas fórmulas de fuentes de información pueden ayudar enriquecer el proceso de aprendizaje del docente gracias al intercambio de intereses, opiniones, experiencias de diferentes personas y nacionalidades. «Como labor previa a cualquier tipo de ejercicio resulta fundamental realizar una selección de materiales que deberá servir de base para las 
actividades que se desarrollen en el aula» (Sanz 2010: 215).

El objetivo está en filtrarlas, analizarlas, reformularlas, asimilarlas y adaptarlas para concebir una nueva obra traducida provocando que el aprendizaje y recreación de las formas de composición escritas en la lengua original concluyan en una mejor traducción que se adapte al lector meta. La relación estructural entre texto y la música, después de siglos, siguen de plena actualidad, pero, gracias a las nuevas tecnologías, tenemos más información que nunca para poder hacer una mejor traducción e interpretación de los Lieder.

En primer lugar, por el interés de los docentes en adaptarse a las exigencias del mundo laboral, que demanda traductores formados en determinados campos de especialidad, y en segundo lugar, por el afán de los investigadores de dotar a la práctica traductora de un entramado teórico que sirva de base a los contenidos didácticos y al modo de transmitirlos. El objetivo fundamental de la enseñanza es el desarrollo de los conocimientos y destrezas necesarios para traducir. La correcta elección del material de trabajo y el tipo de ejercicios adecuados permite configurar un proceso de enseñanza que posibilita al estudiante el aprendizaje (García 2007: 101-102).

La problemática que surge en la traducción de este tipo de textos de más de dos cientos años (como el caso de Erlkönig o El rey de los Elfos) es saber adecuar los textos a la lengua actual, para que los lectores puedan entender la intencionalidad del compositor que musicalizo dicho texto, sin olvidar adaptar dicha traducción al que publico al que van dirigidos. Poder entender e interpretar estas obras desde diferentes puntos de vista, podemos seleccionar varias fuentes como puede ser la partitura original y grabación de grandes barítonos de Erlkönig.

Los cuadros también pueden dar una idea de la temática del tema, la importancia de las imágenes cobra una consideración primordial, esta percepción visual nos puede ayudar a entender ciertos aspectos de la obra, ya que en esa época era una forma de comunicación fundamental para ilustrar y mostrar la temática de las obras, como puede admirarse en diferentes ilustraciones de Erlkönig y darnos una idea del desarrollo de la obra.

En plataformas como YouTube podemos encontrar imágenes audiovisuales donde poder escuchar y ver la obra. Mientras una foto, la audición de la obra musical y un cuadro funcionan por separado, los videos fusionan diversas artes para dar lugar a una nueva obra de arte. Basta con que teclemos Erlkönig para tener miles de videos de diferentes cantantes, épocas, estilos y versiones de este mismo Lied.

En primer lugar, por el interés de los docentes en adaptarse a las exigencias del mundo laboral, que demanda traductores formados en determinados campos de especialidad, y en segundo lugar, por el afán de los investigadores de dotar a la práctica traductora de un entramado teórico que sirva de base a los contenidos didácticos y al modo de transmitirlos (García 2007:101).

En general, una canción tiene una estructura basada en la dialéctica de la repetición y cambios, que nos narra una serie de hechos por parte del letrista y una música que acompaña, es decir el texto y la música se complementan. Las obras literarias son creadas para ser leídas o recitadas y fueron los compositores los que a través de sus composiciones crearon una nueva obra. Por este motivo, es tan importante comprender el texto y la intencionalidad del autor para que los cantantes sepan que están interpretando, adaptándose a la lengua y lector meta, sin olvidar lo que han intentado expresar los literatos para no perder la esencia o finalidad de la obra desde el punto de vista literario y no solamente prestando atención al terreno musical. «El Lied ha sido, sin ninguna duda, lo que ha aportado la contribución más esclarecedora al lenguaje del sentimiento» Fischer-Dieskau (1985: 63).

Así, en el caso de los textos literarios, el traductor habrá de conocer en profundidad aspectos como la vida y la obra del autor del TO, el contexto histórico y social en el cual se enmarca y se gesta la obra literaria, el movimiento o la escuela literarios a la cual pertenecen autor y texto, etc. Es decir, desde un punto de vista no exclusivamente lingüístico, el traductor ha de poseer un conocimiento especializado: funciones del lenguaje, historia de la literatura de la cultura de origen, autores, acontecimientos históricos, culturales y sociales, historia de la lengua de partida, figuras literarias, y otros aspectos extraliterarios que conforman el texto que ha de traducir (Balbuena et al. 2012:4).

Según mi experiencia hay que seguir investigando nuevas formas didácticas para adapatarlas a los alumnos meta, ya que no es lo mismo dar clases a alumnos de una Escuela Oficial de Idiomas que a alumnos de un 
Conservatorio de Música, cuya finalidad varía de forma muy significativa. Lo que se podría traducir en una nueva didactica en la que el docente tiene que encontrar la forma más eficiente para adaptarse a las caracteristicas del alumnado y prepararse para adaptarse al contexto educacional. La traducción y comentario de las partituras y en la relación existente entre el texto y la música es un punto de partida para crear nuevas planificaciones didacticas enfocadas a los alumnos de canto actuales. Es un proceso que requiere mucho tiempo de búsqueda, filtración, elaboración, comprensión y maduración de contenidos para poder crear programaciones didácticas que resulten útiles y productivas a los alumnos. Por eso es tan importante la adecuada elección del material para mejorar el aprendizaje del alumno, ya que tenemos que partir de la base que los alumnos son estudiantes de canto y su finalidad es mejorar su interpretación, no ser expertos traductores.

Por otro lado, el profesorado tiene que dominar no solo la lengua alemana, los movimientos literarios, históricos, además tiene que estar acostumbrado a trabajar con las nuevas tecnologías, ya que son una herramienta que mejora la enseñanza y el aprendizaje por parte del alumnado que ha nacido en un mundo digitalizado.

\subsection{Traducción de la obra y diferentes ejemplos de Traducción}

Wer reitet so spät durch Nacht und Wind?

Es ist der Vater mit seinem Kind;

Er hat den Knaben wohl in dem Arm,

Er faßt ihn sicher, er hält ihn warm.

"Mein Sohn, was birgst du so bang dein Gesicht?"

„Siehst, Vater, du den Erlkönig nicht?

Den Erlenkönig mit Kron und Schweif?“

„Mein Sohn, es ist ein Nebelstreif.“

„Du liebes Kind, komm, geh mit mir!

Gar schöne Spiele spiel' ich mit dir;

Manch bunte Blumen sind an dem Strand,

Meine Mutter hat manch gülden Gewand.“

"Mein Vater, mein Vater, und hörest du nicht,

Was Erlenkönig mir verspricht?"

„Sei ruhig, bleibe ruhig, mein Kind:

In dürren Blättern säuselt der Wind.“

„Willst, feiner Knabe, du mit mir gehn?

Meine Töchter sollen dich warten schön;

Meine Töchter führen den nächtlichen Reihn

Und wiegen und tanzen und singen dich ein.“

„Mein Vater, mein Vater, und siehst du nicht dort

Erlkönigs Töchter am düstern Ort?“

„Mein Sohn, mein Sohn, ich seh es genau:

Es scheinen die alten Weiden so grau."

„Ich liebe dich, mich reizt deine schöne Gestalt; Und bist du nicht willig, so brauch ich Gewalt.“

„Mein Vater, mein Vater, jetzt faßt er mich an!

Erlkönig hat mir ein Leid getan!" 
Dem Vater grauset's, er reitet geschwind, Er hält in Armen das ächzende Kind, Erreicht den Hof mit Müh' und Not: In seinen Armen das Kind war tot.

4.2.1. Ejemplo de traducción obtenida de letras.com. Fuente: (Letras.com, 2021)

¿Quién cabalga tan tarde a través de la noche y el viento?

Es el padre con su hijo

Tiene al chico en su brazo

Él lo sostendrá. Lo mantendrá calentito

Hijo mío, ¿qué tienes tan dura tu cara?

¿Ves, padre, no te gusta el Erlkönig?

¿El Erlenkönig con kron y cola?

Hijo mío, es una niebla

Querida niña, ven, ven conmigo!

Gar hermosos juegos que juego con usted

Algunas flores de colores están en la playa

Mi madre vestía un poco de oro

Mi padre, mi padre, y no te oigo

Lo que Erlenkönig me promete en silencio?

Calma, calma, hija mía

En la sequía deja los vientos del viento

¿Quieres ir conmigo, buen chico?

Deja que mis hijas te esperen maravillosamente

Mis hijas lideran el rango nocturno

Y pesan, bailan y cantan

Mi padre, mi padre, y usted no ve allí

¿Las hijas de Erlkönig están en el lugar oscuro?

Hijo mío, hijo mío, lo veo exactamente

Parece que los viejos pastos tan grises

Te amo, me encanta tu hermosa figura

Y si no estás dispuesto, necesito violencia

Mi padre, mi padre, ahora viene a mí

Erlkönig me ha hecho daño.

El padre Grauset, cabalga rápido,

Él sostiene en brazos al niño gruñendo

Logró la granja con esfuerzo y necesidad

En sus brazos el niño estaba muerto. 
4.2.2. Traducción de Manuel González Prada. Fuente: (Salvador, 2021)

¿Quién galopa a rienda suelta

Entre la sombra y el viento?

Es el padre que en sus brazos

Va llevando al hijo enfermo

$\mathrm{Y}$ en la angustiada carrera

Le ciñe contra su pecho.

- “Por qué te escondes y tiemblas?”.

- “'No ves al Rey de los Elfos, No le divisas, oh, padre,

Con el manto y con el cetro?".

- "Nada temas, hijo amado:

Son las nubes en el cielo".

- "Ven, oh niño, que en mi estancia

Vivirás en mimo eterno;

Vestirás de seda y oro;

Y te hará mi madre el dueño

De la flor de sus jardines,

De la fruta de sus huertos".

- “ ¿No oyes, padre, que me llama

La voz del Rey de los Elfos?",

- "Nada temas, hijo amado: Es el silbido del viento

Entre las ramas del árbol:

Nada temas, ven sin miedo"

- "Ven, oh niño, que mis hijas

Cubrirán tu sien de besos,

$Y$ en la calma de la noche,

Porque a ti descienda el sueño,

Cantarán alegres cantos,

Te dirán sabrosos cuentos".

- “'No ves, padre, a las hermosas

Hijas del Rey de los Elfos?

¿No las ves en el sombrío?”.

- "Son los sauces del sendero

Con su lóbrego ramaje:

Nada temas, ven sin miedo".

- "Te amo oh niño, que me atraes

Por lo hermoso y por lo bueno;

Obedece a mi llamada,

No te esquives a mi ruego, 
Que si tú venir no quieres,

Yo te arrastro, yo te llevo"

- “Padre, se acerca, me coge Me lleva el Rey de los Elfos!”.

Más estrecha el padre al niño;

Corre, vuela con el viento;

Pero al fin de la jornada

Ve al hijo, en sus brazos, muerto.

4.2.3. Traducción propia

¿Quién cabalga tan tarde de noche, con este viento de frente?

Es un padre con su hijo.

Lleva entre sus brazos lleva al chico,

Le sujeta con firmeza, le da calor.

"Hijo mío, ¿por qué escondes con miedo tu rostro?"

"Padre, ¿no ves al rey de los elfos

Con su corona y cabellera?"

"Hijo mío, es un filamento de niebla."

“ Oh querido niño, vente conmigo!

A bonitos juegos jugaré contigo;

En la orilla hay flores de mil colores,

Y mi madre tiene muchos ropajes dorados."

"Padre mío, padre mío, ¿no oyes acaso

Lo que me promete el rey de los elfos?".

"Tranquilo, tranquilizate mi niño,

Entre las hojas secas susurra el viento."

"Querido niño, ¿no quieres venir conmigo?

Mis hijas de ti cuidaran;

Te esperan deseosas para acunarte,

Bailaran y cantaran para ti."

"Padre mío, padre mío, ¿no ves allí en la sombra,

A las hijas del rey de los elfos?"

"Hijo mío, hijo mío, lo veo claramente:

Son los viejos pastos que parecen tan grises."

"Te amo, me tanto enamora tanto tu hermosa figura;

Y si no vienes de forma voluntaria, usaré la fuerza."

“¡Padre mío, padre mío, ahora me está tocando!

¡El rey de los alisos me ha hecho daño!”

El padre se asusta y cabalga velozmente,

Sostiene en sus brazos al niño llorando. 
Llega a su hogar con angustia y sin aliento:

Entre sus brazos, el niño yacía muerto.

\subsection{Comentario e interpretación de Erlkönig}

Erlkönig (Opus 1, Deutsch-Verzeichnis D328) es un Lied compuesto por Franz Schubert en un solo día (se desconoce la fecha exacta de su composición, pero se situaría entorno al otoño de 1815) por un joven Schubert de tan sólo dieciocho años. Se trata de un Lied escénico o declamado que narra el cuento original sobre la leyenda del Rey de los Elfos de aparecerse ante los vivos anunciándoles una inminente muerte.

La muerte se muestra como cautivadora por parte del rey de los Elfos y como el mejor destino para el niño sin tener en cuenta los sentimientos del padre que cabalga furiosamente para salvarle de su destino, la muerte. Schubert logra reflejar a través de la música, y en especial del piano, los cambios de tonalidad, y un solo cantante es capaz de interpretar a cada uno de los cuatro de los personajes: el narrador, el padre, el hijo y el rey de los Elfos.

Los alumnos son nativos digitales y su principal fuente de búsqueda de información es Google y Wikipedia, en cuanto pides que hagan búsquedas siempre acaban copiando textos como este sacados de dichas webs. El problema es que hay que filtrar la información y explicarles con datos lingüísticos, literarios, mitológicos que hoy en día les parecen ridículos e inverosímiles. Un ejemplo de ello es el hecho de que un Rey venga a arrebatar a un niño de los brazos de su padre, el cual huye para no tener que entregar a su hijo ignorando que no podrá escapar de un final y doloroso ya que no tiene ninguna posibilidad de cambiar su destino.

De acuerdo con el folclore alemán y danés, el Rey de los Elfos aparece como presagio de la muerte, parecido a la banshee en la mitología irlandesa, pero a diferencia de la banshee, el Rey de los Elfos solo se aparece a la persona que va a morir. Su forma y expresión le dicen a la persona qué tipo de muerte tendrá: una expresión de dolor significa una muerte dolorosa mientras que una expresión pacífica una muerte tranquila. Otra interpretación sugiere que la leyenda dice que cualquiera que toque al Rey de los Elfos debe morir (Wikipedia 2021).

\subsubsection{Comentario de las traducciones}

En el primer ejemplo, la traducción tiene partes incomprensibles. El dominio de la lengua origen es un requisito fundamental, así como el conocimiento de la cultura, tradiciones e historia germánica; sin olvidar conocimientos de poesía, rima, métrica, ritmo tanto en la lengua de origen como en la meta. Goethe basó su poema en Erlkönigs Tochter (La hija de Erlkönig), una obra danesa traducida al alemán por Herder, el cual mantuvo esta denominación al traducirla para que sonara similar al original danés, Ellerkang (rey de los elfos). Para ello utilizó la expresión Erlkönig, que en realidad significa rey de los alisos ${ }^{1}$, en lugar de Elfenkönig (El rey de los Elfos) criaturas mágicas de la literatura nórdica y germánica. Esta información es fundamental para poder comprender el texto, ya es el Rey de los Elfos (no un árbol) que persigue al hijo mientras el padre cabalga velozmente para poder salvarle la vida.

Si profundizamos en la página vemos que se trata de una traducción automática realizada por el traductor automático de Amazon, el cual desconoce el origen del Lied y simplemente sustituye palabras en alemán por palabras en castellano. Traducir arte es muy complicado ya que es una actividad humana, con una finalidad estética, donde se retratan aspectos (reales o inverosímiles) a través de materia, palabras, imágenes o sonidos. Pero sobre todo, es la expresión de los autores sobre su concepción de la vida y lo que sintieron realizando estas actividades o simplemente el hecho de plasmar la acción que tenga un sentido para ellos.

En el segundo caso, se trata de una traducción de González Prada. Su enfoque consiste en estudiar el poema sobre todo de manera estructural, en la que los sentimientos que él ha experimentado al leerla. La traducción del poema se estructura en ocho estrofas de cuatro líneas cada una, buscando su igual en castellano y adaptando con cambios significativos para cuadrar la rima. De esta forma la incertidumbre y el apasionamiento dramático se expresan a través de un nuevo compás silábico que permite continuar la acción desarrollada en versos más largos.

González Prada refuerza con su traducción la tensión del poema ya de por si lacónica en el original, para alcanzar el trágico colofón. El destino ya estaba escrito, el niño tenía que morir.

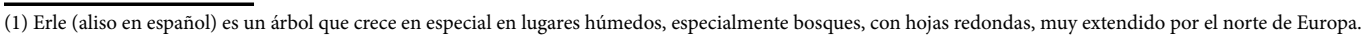


Los diferentes sentimientos de los protagonistas sobre la muerte como elemento fundamental como medio de expresión oral. Es un nuevo poema lleno de mitos, leyendas y tradiciones populares, producen una fuerza comunicativa a través de la rima que supera al poema original. Es evidente que González Prada era un experto de las formas poéticas, vanguardista e innovador en el aérea de la traducción recreativa. Reformula la estructura del poema, creando una nueva obra literaria que guiara, orientara al lector hacia una nueva senda que le permitiera extraer nuevas sensaciones, ideas y conclusiones sobre el poema original de Goethe.

Manuel González Prada apunta en la década del ochenta del siglo XIX, la necesidad de integrar a la literatura escrita en lengua española elementos propios de la balada de cuño alemán, tales como el objetivismo y el dramatismo. Estos elementos y su puesta en práctica en baladas compuestas por el poeta peruano le permiten proponer al crítico que se trata de uno de los primeros "proyectos de renovación poética intentados en el Perú". Proyecto que, sin duda, se inicia con la traducción de las baladas alemanas y que luego lleva a González Prada a crear las suyas (Salvador 2021: 154).

Esta segunda traducción es muy específica y se centra mucho en el contenido lingüístico, literario haciendo énfasis en la importancia de la rima, estrofa o acentuación. No es lo mismo traducir para alumnos de conservatorios de música, cuya finalidad es interpretar una obra musical con su máxima perfección vocal, que traducir para lectores de poesía, cuya finalidad es el placer de una lectura. La finalidad del lector meta (alumnos de conservatorios o escuelas de música) es interpretar la obra musical, sin olvidar que no deben relegar el texto a un segundo plano u olvidarlo por la priorización de la interpretación vocálica. Es fundamental para el alumno que canta un Lied comprender que no es lo mismo cantar al amor que a la muerte y que, aunque no dominen la lengua alemana, con una buena traducción pueden mejorar su interpretación.

En el tercer caso, he intentado adecuar el Lied a alumnos de canto de conservatorios de música, alumnos que necesitan una traducción de la obra, así como un breve comentario (que el docente puede entregar en clase de forma escrita o de forma oral en el aula) para entender por qué compositores como Schubert o Schumman seleccionaron obras de Goethe, Schiller o Heine para producir sus respectivas obras musicales llegando a las más altas cotas del arte moderno y contemporáneo fusionando historia, política, mitología, literatura, humanismo, romanticismo entre otras disciplinas.

\section{Conclusiones}

La traducción y comentario de los Lieder permite el tratamiento directo de los aspectos lingüísticos-literarios en relación con la partitura. La idea es que el alumno-cantante a la hora de interpretar estas obras conozca lo que intentaban transmitir los autores para que pueda expresarlo a través del canto. La traducción y adaptación al lector meta es la finalidad; que el alumno-cantante comprenda la intencionalidad no solamente del compositor, sino también del autor de los textos. El estudio y el análisis de un Lied desde el punto de literario, con la finalidad de obtener una adecuado y riguroso comentario de la obra, es solamente el principio del aprendizaje-fusión de varias asignaturas enfocadas en la adaptabilidad de las planificaciones del alumnado meta dentro del aprendizaje de las lenguas extranjeras.

Las nuevas tecnologías nos han ayudado a acceder a diferentes fuentes de conocimiento hasta ahora inexistentes y plantean un gran desafío que concluye en la apertura de nuevas ventanas a nuevas formas de aprendizaje. Introducir las nuevas tecnologías como un nuevo recurso de aprendizaje (siempre filtrando las fuentes) diversifica la metodología y contribuye a mejorar la motivación del alumnado y dejando de lado métodos de enseñanza anteriores que solamente se basaban en la interpretación del Lied a través del automatismo, con traducciones mediocres que no llegaban a comprender.

El desafío que se les plantea a los docentes para adaptarse a los nuevos alumnos-digitales es enorme ya que estos reclaman otro tipo de aprendizaje. Es fundamental buscar, filtrar, seleccionar, reorganizar, reestructurar, adaptar y en algunas ocasiones recrear la traducción, lo cual implica muchas horas de preparación. La idea es que los docentes de este tipo de asignaturas puedan introducir en sus planificaciones, estrategias didácticas con un nuevo enfoque en el que se anexionen tres especialidades: música, lengua y literatura. Desgraciadamente el currículo actual no es capaz de reflexionar sobre las fortalezas de esta fusión de materias a largo plazo y 
una implantación de una planificación con una normativa integradora se hace fundamental para poder seguir adaptándonos a los nuevos retos de este siglo, identificando y diseñando nuevas herramientas educativas que se adapten a los diferentes tipos de alumnado.

Bibliografía:

Balbuena, C. (2012). Entre la Filología y la Traducción: la labor del traductor literario. En M., Pfeiffer, T., Vinardell i Puig y A. Montané (coord.), Was mich wirklich interessiert. Homenatge a Jordi Jané. (pp 37-46). Editorial Documenta Universitaria Girona.

Cardó, A. (2017). El Lied romántico alemán. Alianza música.

Carreras, J. J. (1998). La música y sus nombres. [Reseña del libro Diccionario Harvard de Música, de D. M. Randel]. Revista de libros segunda época, 13. https://www. revistadelibros.com/diccionario-harvard-demusica

Der Erlkönig. (13 de octubre de 2021). En Wikipedia. https://es.wikipedia or g/w / i n d ex.ph p ? t i t l e = D e r Erlk\%C3\%B6nig\&oldid $=139025592$

Einstein, A. (1986). La música en la época romántica. Alianza música.

Elena García, P. (2007). Reflexiones en torno a la enseñanza de la traducción especializada. Panace@, 26, 101-102. https://www. tremedica.org/wp-content/uploads/n26 editorial.pdf
Fischer-Dieskau, D. (1985). Hablan los sonidos, suenan las palabras. Ediciones Turner.

Goethe J. W. [OxfordLieder] (15/11/2013) Franz Schubert: Erlkönig [vídeo]. https:// youtu.be/JS91p-vmSf0.

Gomar, A. B. (2005). Stimmung, Un ensayo sobre la mística musical. Espacio Sonoro, 7, 1-34. http://espaciosonoro.tallersonoro. com/wp-content/uploads/2019/08/AnalisisStimmung.pdf

Letras (s.f.). Erlkönig. https://www.letras.com/ franz-schubert/erlkonig/traduccion.html

Maldonado, M. y Hernández, I. (2003). Literatura alemana. Epocas y movimientos desde los orígenes hasta nuestros días. Editorial Alianza.

Massin, B. (1997). Franz Schubert Bibliografia. Ediciones Turner.

Pacheco, J. y Vera, C. (1998). El romanticismo europeo. Universidad de Sevilla.

Reverter, A., Cardó, A., Schmidt, S., Gragera, E., Viribay, A., Carril, J. y Alonso, L. (2008). El nacimiento del Lied. https://www. march.es/es/madrid/nacimiento-lied

Salvador, L. (2021). Manuel González Prada y la traducción como recreación: el caso de
"Erlkönig" de Johann Wolfgang Goethe Revista Cadernos de Tradução, 41(1), 148-170. https://doi.org/10.5007/21757968.2021.e77113

Sanz Julián, M. (2008). Propuestas didácticas para la enseñanza del Alemán aplicado al Canto. En Pichler, G., Haus B., Benito, M., García I. y Ortiz de Urbina P. (coord.), Germanística y enseñanza del alemán en España (pp. 215-224). Editorial Idiomas.

Sopeña Ibañez, F. (1973). El Lied romántico. Moneda y Crédito.

Valencia Restrepo, D. (2021). Poesía y música en las canciones de Schubert. https:// www.valenciad.com/LiederSchubert/ LiederSchubert.pdf

Walker, S. y Vignoles, R. (1989). Erlkönig [Canción]. The Great Schubert Singers. Brillant Classic. 